\title{
Does positive pressure ventilation increase arginine vasopressin in preterm neonates?
}

\author{
Heather J Lambert, Peter H Baylis, Judith A McAulay, Malcolm G Coulthard
}

\begin{abstract}
Aim-To examine the effect of intermittent positive pressure ventilation (IPPV) on plasma arginine vasopressin concentration (pAVP) in preterm neonates.

Methods-Thirty five neonates were classified, at the time of blood sampling, into three groups: unstable ventilated; stable ventilated; and stable non-ventilated. A modification of an extraction method for pAVP was developed for use in studies on very small babies, and sampling methods were compared.

Results - The pAVP (median, range) was similar in the ventilated $(1.85 \mathrm{pmol} / 1,0.5$ to $3.4)$ and non-ventilated $(2.0,0.5$ to 2.6$)$ stable babies, but was significantly higher $(5.7,1.1$ to 25$)$ in the unstable group. There was an inverse correlation between systolic blood pressure and pAVP concentration.

Conclusions-This study shows that in preterm neonates pAVP concentration is affected by the clinical condition and blood pressure, but not by treatment with IPPV.
\end{abstract}

(Arch Dis Child Fetal Neonatal Ed 1998;78:F38-F42)

Keywords: arginine vasopressin; assisted ventilation; systolic blood pressure

Department of Child Health, University of Newcastle upon Tyne H Lambert

Department of

Medicine

P Baylis

J McAulay

Department of Paediatric Nephrology, Royal Victoria Infirmary, Newcastle upon Tyne M Coulthard

Correspondence to: Dr H J Lambert

Department of Child Health

Royal Victoria Infirmary

Royal Victoria Infirmary

NIP.

Accepted 18 July 1997

Table 1 Details of groups median (range)

\begin{tabular}{lccc}
\hline & $\begin{array}{l}\text { Ventilated unstable } \\
(n=14)\end{array}$ & $\begin{array}{l}\text { Ventilated stable } \\
(n=11)\end{array}$ & $\begin{array}{l}\text { Non-ventilated stable } \\
(n=10)\end{array}$ \\
\hline $\begin{array}{l}\text { Gestational age (weeks) } \\
\text { Birth weight }(\mathrm{g})\end{array}$ & $28(25-31)$ & $29(24-34)$ & $28(28-33)$ \\
Age at time of study $(\mathrm{h})$ & $1057(740-1605)$ & $\begin{array}{c}1170(505-2015) \\
49(36-120)\end{array}$ & $\begin{array}{c}1105(665-1704) \\
44(24-120)\end{array}$ \\
\hline
\end{tabular}

Arginine vasopressin (AVP) is released in response to osmotic and non-osmotic stimuli in humans and most animals. Non-osmotic stimuli are numerous but the most potent include hypotension and hypovolaemia. It has been suggested that intermittent positive pressure ventilation (IPPV) is a cause of the syndrome of inappropriate anti-diuretic hormone secretion (SIADH) in adults. ${ }^{1-4}$ In neonates, SIADH has been reported in mechanically ventilated neonates with pneumothorax. ${ }^{5}{ }^{6} \mathrm{AVP}$ is reported to be increased in preterm neonates receiving mechanical ventilation for respiratory distress syndrome secondary to surfactant deficiency (RDS).$^{78}$ It is common practice in some neonatal units for ventilated neonates to receive routinely restricted fluid volume. This study was performed to examine the effect of IPPV on plasma concentration of arginine vasopressin (pAVP) in preterm neonates.
Under normal circumstances the concentration of the anti-diuretic hormone AVP is very low in human plasma. Measurement necessitates a large volume of plasma, an extraction procedure, and a sensitive assay. The large sample volume required poses major problems in studies of neonates. We therefore developed a modification of an extraction procedure ${ }^{9}$ to permit measurement of pAVP on small samples (50-100 $\mu \mathrm{l}$ of plasma), if sampling was performed at a time when other biochemical measurements were required. Only some neonates have an arterial sampling line in situ and it is therefore not considered justifiable to insert one purely for study purposes, so sampling methods were compared.

\section{Methods}

Thirty five preterm babies in a regional neonatal unit in Newcastle upon Tyne were studied (table 1). All were nursed in enclosed incubators and given fluid volumes according to the unit's normal protocol (increasing stepwise from $80 \mathrm{ml} / \mathrm{kg}$ birthweight/day on day 1 to 150 $\mathrm{ml} / \mathrm{kg}$ on day 5 ).

The babies were classified into three groups: stable, non-ventilated; stable, ventilated; unstable (all of whom were also ventilated). The categorisation was determined according to the following criteria, and carried out at the time of blood sampling and with knowledge of the blood gas results (which were immediately available) and before any other results had been obtained:

A stable baby was one who:

(i) was considered well on general clinical examination;

(ii) had blood results: $\mathrm{pH}>7.25$ and $\mathrm{pCO}_{2}<$ $8 \mathrm{kpa}$

(iii) had a "normal" blood pressure within published ranges ${ }^{10-12}$ which was not consistently falling;

(iv) had had no "events" during the previous 24 hours, defined as anything untoward, such as pneumothorax, clinically suspected or confirmed infection, cardiovascular collapse, etc.

Any baby not fulfilling all of these criteria was classified as "unstable."

Blood was sampled when it was clinically required for measurement of electrolytes. An indwelling arterial line was used if present (in all the ventilated and some of the nonventilated babies), otherwise venepuncture was performed. The blood was collected on ice and separated, as described. Extraction of AVP from plasma was performed immediately so that routine biochemistry results were available to the clinicians without delay. 
MODIFICATION OF AVP EXTRACTION

This modification of the method of Rooke and Baylis ${ }^{9}$ involved reusing rather than discarding plasma after Florisil extraction of AVP, for subsequent measurement of electrolytes and creatinine. It enabled pAVP to be measured with only a requirement of $100-150 \mu$ of extra blood. To validate the modification, blood from the umbilical cord artery of five fresh placentas and venous blood from five normal adult volunteers was taken. Samples were drawn into pre-cooled syringes, transferred to chilled plastic tubes containing lithium heparin, rapidly cooled in ice and centrifuged at $3000 \mathrm{rpm}$ at $4^{\circ} \mathrm{C}$ within 10 minutes, and the plasma was aspirated and immediately frozen and stored at $-40^{\circ} \mathrm{C}$. After thawing plasma samples were divided and biochemistry measurements were performed before and after Florisil extraction of AVP. Plasma sodium and potassium were measured using an ion selective electrode, urea using spectrophotometric diacetyl monoxime, and creatinine using a modified Jaffe reaction, all with an SMAC II analyser (Technicon Instruments, Tarry Town, NY, USA). Magnesium was measured by atomic absorption (Perkin Elmer 2380 spectrophotometer, Perkin Elmer Instruments, Norwalk, CT, USA).

To extract the AVP, $500 \mu \mathrm{l}$ of plasma was mixed with about $20 \mathrm{mg}$ of "activated" Florisil (magnesium silicate, 100-200 mesh, Sigma F7752) for 20 minutes at room temperature in a silicon coated glass tube. The Florisil was allowed to settle at the bottom of the tube, and the plasma was carefully aspirated for biochemical analysis instead of being discarded (as in the original method). More than $80 \%$ of the initial plasma volume was recoverable. The Florisil was then washed using distilled water, followed by 0.2 molar hydrochloric acid. The AVP was then eluted from the Florisil with $90 \%$ acetone and separated using diethyl ether, and dried under a stream of nitrogen. The double antibody radioimmunoassay for AVP described by Rooke and Baylis ${ }^{9}$ was subsequently used.

The results showed that the plasma concentrations of sodium, potassium, urea and creatinine were unaffected by the extraction process (table 2), but plasma magnesium concentration was higher after extraction (paired $t$ test; $\mathrm{p}<0.005$ ).

Standard curves plotted using extractions from cord plasma ran parallel to those using normal adult volunteer plasma. Recovery of AVP added to cord plasma was $96 \%$ at $5 \mathrm{pmol} / 1$ and $90 \%$ at $10 \mathrm{pmol} / \mathrm{l}$, using the modified extraction method. Using cord plasma the intra-assay coefficient of variation $(\mathrm{CV})$ was

Table 2 Mean (SD) plasma biochemistry results pre and post mixing with Florisil using adult and cord plasma

\begin{tabular}{|c|c|c|c|c|c|}
\hline & \multirow[b]{2}{*}{ Units } & \multicolumn{2}{|c|}{ Adult (5 samples) } & \multicolumn{2}{|c|}{ Cord (5 samples) } \\
\hline & & pre & post & pre & post \\
\hline Sodium & $\mathrm{mmol} / 1$ & $139(1.6)$ & $139(1.5)$ & $137(1.6)$ & $138(1.9)$ \\
\hline Potassium & $\mathrm{mmol} / 1$ & $4.0(0.19)$ & $4.0(0.1)$ & $4.0(0.3)$ & $4.1(0.4)$ \\
\hline Urea & $\mathrm{mmol} / 1$ & $4.3(0.7)$ & $4.3(0.8)$ & $4.4(0.8)$ & $4.3(0.7)$ \\
\hline Creatinine & $\mathrm{umol} / 1$ & $77(10.9)$ & $78(10.8)$ & $88(5.5)$ & $88(3.7)$ \\
\hline Magnesium & $\mathrm{mmol} / 1$ & $0.8(0.05)$ & $1.2(0.10)$ & $0.8(0.03)$ & $1.1(0.09)$ \\
\hline
\end{tabular}

Table 3 Plasma AVP concentration sampled via different routes

\begin{tabular}{llc}
\hline & \multicolumn{2}{l}{ Plasma AVP in pmoll from } \\
\cline { 2 - 3 } Patient & Arterial line & Venepuncture \\
\hline 1 & 1.9 & 2.2 \\
2 & 2.6 & 2.0 \\
3 & 1.5 & 1.4 \\
4 & 0.8 & 1.1 \\
5 & $\leqslant 0.5$ & 2.5 \\
6 & 2.8 & 2.4 \\
& (limit of detection $0.5 \mathrm{pmol} / \mathrm{l})$ \\
\hline
\end{tabular}

$5.4 \%(n=10)$ and the interassay $\mathrm{CV}$ was $11.5 \%$. $(\mathrm{n}=20)$ at $2 \mathrm{pmol} / \mathrm{l}$.

Thus, plasma was "reused" after extraction of AVP with Florisil for measurement of plasma sodium, potassium, urea and creatinine, therefore reducing the extra volume of plasma required solely for study purposes by at least fivefold. Physiological validation of the method by hyperosmolar saline infusion or lowering of blood pressure in neonates was not considered ethically justifiable and was therefore not performed.

VALIDATION OF BLOOD SAMPLING METHOD

This comparison was performed as it was recognised that not all babies in neonatal units have arterial or other blood sampling lines in situ, and because AVP may be released in response to the pain of venepuncture.

Six babies were studied who were not part of the main study. They were selected because they were well and had arterial lines in situ but also required a venepuncture for a clinical indication (insertion of intravenous cannula or blood sampling for clotting studies). A blood sample was taken from the arterial line immediately before venepuncture. All samplings were performed by one researcher (HJL) and were completed within 5 minutes, with minimal disturbance to the baby. The pair of samples were processed identically and the pAVP measured in the same assay. Verbal

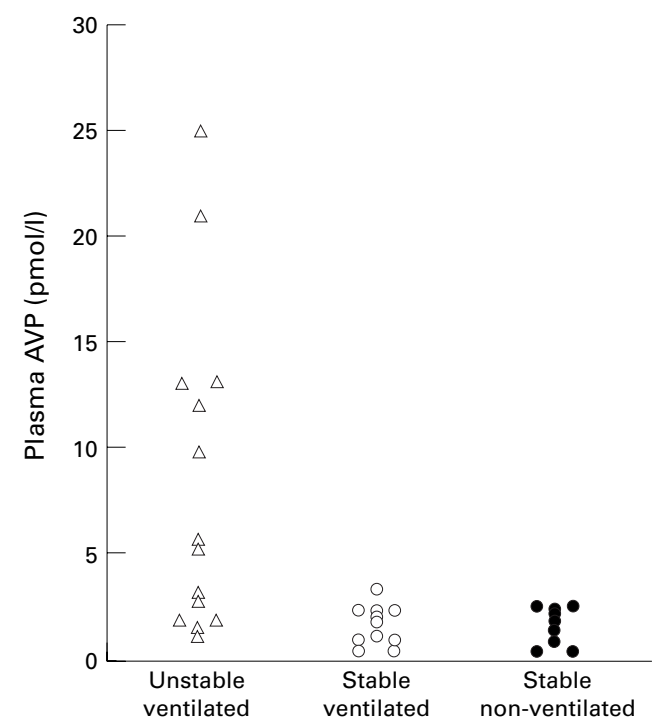

Figure 1 Plasma AVP concentration in three groups of preterm neonates: unstable ventilated; stable ventilated; and stable non-ventilated. 


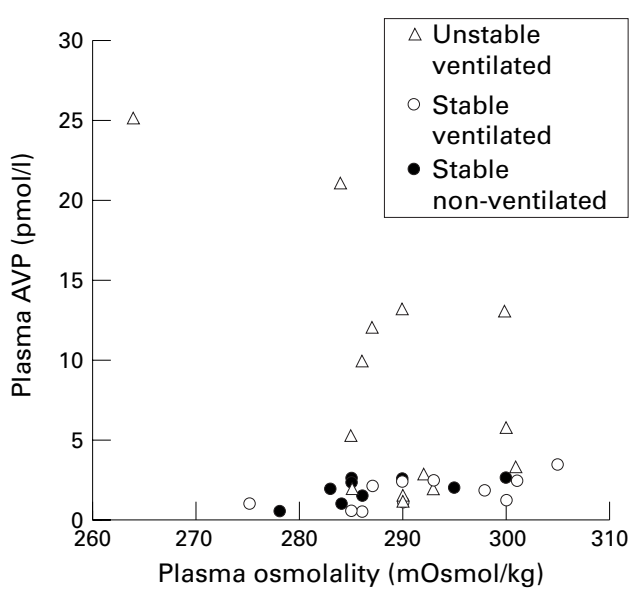

Figure 2 Relation between plasma AVP concentration and plasma osmolality.

parental consent was obtained for the extra blood volume (about $2 \mathrm{ml}$ ) taken.

There was no statistical difference shown (paired $t$ test; $\mathrm{p}=0.6$ ) nor trend observed between the two sets of results, and differences were within the variation of the methods used (table 3).

\section{OTHER MEASUREMENTS}

Urine samples were collected by placing the baby on an upturned nappy at the time of blood sampling and collecting the urine in a syringe as soon as the baby had voided. Plasma and urine osmolality were measured by depression of freezing point (Camlab MOD200), the $\mathrm{CV}$ being $0.5 \%$ at $300 \mathrm{mOsm} / \mathrm{kg}$.

Systolic blood pressure was measured directly using an arterial line transducer in all of the unstable ventilated, stable ventilated babies and some of the non-ventilated babies; and with an automatic BP machine (Dynamap) in those stable non-ventilated babies without arterial lines. Details of the babies' ventilation requirements and blood gases were also noted at the time of blood sampling and classification into stable and unstable made at that time.

Non-parametric tests were used for statistical analysis of the main study. Approval for the studies was obtained from the Newcastle District Health Authority/University Joint Ethics Committee.

\section{Results}

Plasma AVP values for the babies in the three groups are shown in fig 1 . The median (range) pAVP concentration in the unstable ventilated group was 5.7 (1.1 to 25), in the stable ventilated group 1.85 (0.5 to 3.4$)$, and in the stable non-ventilated group 2.0 (0.5 to 2.6 ) $\mathrm{pmol} / \mathrm{l}$. There was no significant difference in pAVP between the stable ventilated and stable non-ventilated babies (Mann-Whitney U test; $p=0.8$ ), but pAVP was higher in the unstable group than in either of the stable groups $(\mathrm{p}<$ $0.01)$.

There was no significant relation between plasma AVP concentration and either plasma or urine osmolality (figs 2 and 3 ).

All the stable babies had systolic blood pressure within the expected range from published data as this was part of the criteria for their

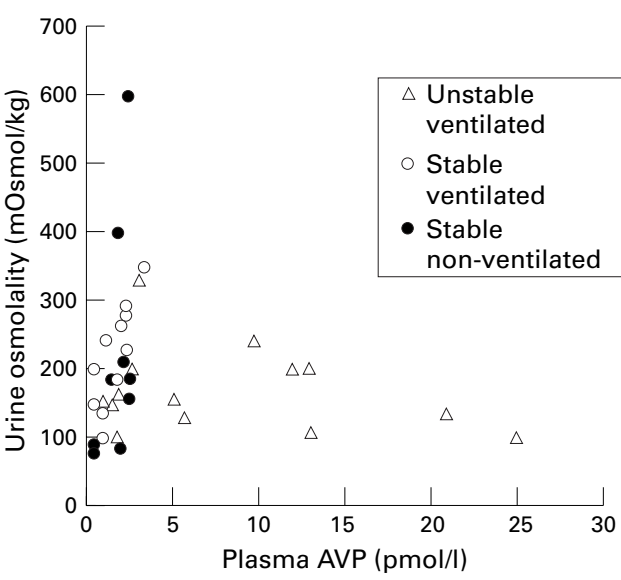

Figure 3 Relation between urine osmolality and plasma AVP concentration.

selection as "stable." Within this group there was no relation between systolic blood pressure and $\mathrm{pAVP}$. There was a negative correlation between pAVP and systolic blood pressure when all the babies were considered together (Spearman rank correlation coefficient -0.69 ; $\mathrm{p}<0.01$ ), and when the unstable group was considered separately (Spearman rank correlation coefficient $-0.65 ; \mathrm{p}<0.01$ ) (fig 4 ).

As expected, the babies in the unstable group had lower systolic blood pressure than those in the ventilated and non-ventilated stable groups (Mann-Whitney U test; $\mathrm{p}<0.005$ ). There was no difference in systolic blood pressure between ventilated and non-ventilated babies $(p=0.13)$ within the stable groups.

The median (range) peak/minimum ventilator pressure in the unstable group was 30/3 (18 to $36 / 2$ to 5 ), and $25 / 3$ (11 to $30 / 2$ to 4 ) $\mathrm{cm}$ water in the stable ventilated group. There was no relation between ventilator pressures and pAVP.

\section{Discussion}

This study shows that babies classified clinically as unstable have higher concentrations of pAVP and a wider range of values than babies classified as stable, and that babies classified as stable had similar values of pAVP whether or not they were receiving IPPV. If the data from the present study were analysed by grouping

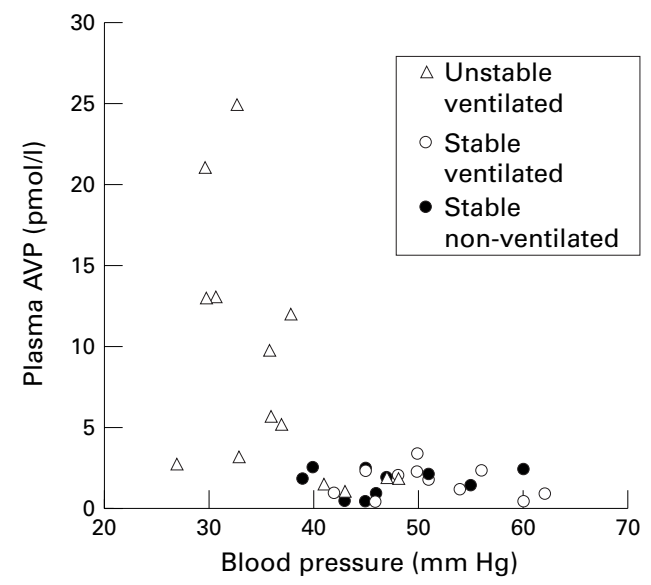

Figure 4 Relation between plasma AVP concentration and systolic blood pressure. 
the results from all the ventilated babies together (unstable and stable) and comparing the results in that group with those obtained in non-ventilated babies, then it could be concluded that ventilated babies have higher pAVP than non-ventilated babies. However, when pAVP values are compared between stable babies receiving IPPV and stable babies not receiving ventilatory support, no difference is found. Thus IPPV itself does not seem to be a cause of raised pAVP. Our criteria for classifying babies are empirical and the unstable group particularly were somewhat heterogeneous, but if this group contained some babies who were less severely ill than others it further supports our findings that IPPV is not a cause of raised pAVP. Previous studies reporting an increase in AVP in ventilated babies have only studied very sick infants ${ }^{7}$ or babies with additional problems such as pneumothorax ${ }^{5}$ or intracranial injury. ${ }^{13}$ Our study shows that results from babies with differing clinical conditions can substantially skew the data and alter conclusions.

It is commonly believed that pAVP is increased or that SIADH occurs in patients receiving IPPV. ${ }^{14-16}$ This is based on data from animal experiments ${ }^{17}$ and adult clinical studies. ${ }^{2}$ In animal experiments well animals are ventilated electively and may receive anaesthetic agents or sedation which could affect release of AVP. Ventilator pressures, which may be very different from those used clinically, may also affect haemodynamic status and AVP release, and thus conclusions of studies. ${ }^{17}{ }^{19} \mathrm{In}$ adult clinical studies the patients may have other complicating medical conditions; they may or may not have intrinsic lung disease, but they do not have RDS secondary to surfactant deficiency, this being the major indication for assisted ventilation of preterm babies. Babies with RDS have poor lung compliance and thus the effect on intrathoracic pressures and the haemodynamic consequences will be different than in experimental animals and adults.

Higher urinary AVP excretion has been reported in very low birthweight babies receiving assisted ventilation compared with those with spontaneous respiration on postnatal day 1 but not on day $2 .{ }^{20}$ Increased urinary AVP concentration and decreased urine output have been reported in neonates during treatment with continuous positive airways pressure (CPAP) at high pressures $(8 \mathrm{~cm}$ water $) .{ }^{21}$ In neither study was pAVP measured. In a study of adults ventilated for neurological disease no evidence of increased AVP release was shown during positive end expiratory pressure (PEEP) of $15 \mathrm{~cm}$ water compared with zero PEEP, although reduced urine output was observed. ${ }^{22}$ In the present study babies receiving CPAP were not studied, and the PEEP was normally between 2 and $4 \mathrm{~cm}$ water. There was no relation between peak inspiratory pressure or PEEP and pAVP. Further studies on neonates involving assessment of transthoracic pressure-for example, by means of intraoesophageal pressure transducer-together with assessment of cardiac output, might be informative.
This study found no correlation between pAVP and plasma osmolality under these clinical circumstances, which agrees with other reports of a minimal or absent correlation. ${ }^{82324}$ Thus it must be concluded that AVP is released in babies in response, at least in part, to non-osmotic stimuli. Release of AVP in response to non-osmotic stimulation has been well described in adults and experimental animals. Most studies in adults showing the relation between increased plasma osmolality and release of AVP have subjected individuals to an experimental increase in plasma osmolality (for example, by dehydration or infusion of hypertonic saline). It is not possible, because of practical and ethical considerations, to repeat such studies in neonates, thus making the contribution of changes in plasma osmolality to AVP release difficult to assess.

A poor urinary concentrating response to plasma AVP was shown in this study, with some of the babies that had the highest plasma AVP values still producing hypo-osmolar urine; there was no correlation between urine osmolality and plasma AVP concentration. This finding agrees with other studies which show no relation or a poor urinary concentrating response to AVP in some preterm neonates. ${ }^{832526}$ The explanation for this finding is unclear. It is well established that neonates are unable maximally to concentrate their urine in relation to healthy adults and this is thought to be related to the newborn's less effective intrarenal concentrating gradient and a relatively poorer end organ responsiveness to AVP. It may also be explained by methodological problems relating to the timing of the pAVP measurement in relation to the urine collection; or it may be that a single measurement does not reflect the rapid changes in pAVP that can take place over a short period of time.

It was not the intention of this study to compare different methods of blood pressure measurement and therefore the method already in use clinically on the babies during the study was continued. All of the babies who were ventilated had blood pressure measured by arterial line transducer. These were the babies most likely to have "abnormal" blood pressure. Although it can be argued that there are no true "normal" ranges for blood pressure in preterm babies, there are data on ranges found in preterm neonates ${ }^{10-12}$ and these show that blood pressure increases with gestational and postnatal age. It is not surprising that in those babies with blood pressure within the expected ranges, no relation was seen between systolic blood pressure and pAVP. There was a significant negative correlation between systolic blood pressure and pAVP, overall, and in the unstable group, and this agrees with the data from many animal and adult studies, which show a release of AVP with hypotension. Some of the unstable babies seemed to be hypotensive but did not have high plasma AVP concentrations. Although these babies might have been unable to produce high concentrations of AVP, it is perhaps more likely that our 
assessment of what is a "normal" blood pressure for a particular baby is limited.

In conclusion, this study shows that in preterm newborns pAVP is affected by the clinical condition and systolic blood pressure, but not by treatment with IPPV.

We are grateful to the nursing and medical staff of the neonatal unit of Newcastle General Hospital for their help and support. HJL was supported by Medical Research Council project gran G87177585A. We thank Newcastle CHILD Fund for additional financial support.

1 Sladen A, Laver MB, Pontopiddan H. Pulmonary complications and water retention in prolonged mechanical ventilation. N Engl F Med 1968;279:448-53.

2 White WA, Bergland RM. Experimental innappropriate ADH secretion caused by positive pressure respirators. $\mathcal{F}$ Neurosurg 1972;36:608-13.

3 Hemmer M, Viquat CE, Suter PM, Valloten MB. Urinary antidiuretic hormone excretion during mechanical ventilation and weaning in man. Anaesthesiology 1980.52:395400 .

4 Kinter LB, Dubb J, Huffman W, et al. Potential role of vasopressin antagonists in the treatment of water retaining dispressin antagonists in the treatment of water retaining disPress, 1985:553-61.

5 Paxson CL, Stoerner JW, Denson SE, Adcock EW, Morriss FH. Syndrome of inappropriate antidiuretic hormone FH. Syndrome of inappropriate antidiuretic hormone secretion in neonates with

6 Stern P, Larochelle FT, Little GA. Vasopressin and pneumothorax in the neonate. Pediatrics 1981;70:773-83.

7 Rees L, Brook CGD, Shaw JCL Forsling ML. Hyponatrae$\mathrm{mia}$ in the first week of life in preterm infants. Part Arginine vasopressin secretion. Part II. Sodium and water excretion. Arch Dis Child 1984;59:414-29.

8 Takata M, Takahaski H. Effects of antidiurectic hormone (AVP) and human atrial natriuretic peptide (hANP) on water and electrolyte balance in neonates. Acta Paediat 7pn 1988;30:146-54.

9 Rooke P, Baylis PH. A new sensitive radioimmunoassay for plasma arginine vasopressin. F Immunoassay 1982;3:11531 .

10 Broughton Pipkin F, Smales ORC. A study of factors affecting blood pressure and angiotensin II in newborn infants. 7 Pediatr 1977;91:113-19.

11 Versmold HT, Kitterman JA, Phibbs RH, Gregory GA Tooley WN. Aortic blood pressure during the first 12 hours of life in infants with birth weight 610 to 4222 grams. Pediatrics 1981;67:607-13.

12 Weindling AM. Blood pressure monitoring in the newborn. Arch Dis Child 1989;64:444-7.

13 Moylen MB, Herrin JT, Krishnamoorthy K, Todres D, Shannon DC. Inappropriate antidiuretic hormone secretion in premature infants with cerebral injury. Am 7 Dis Child 1978;132:399-402.

14 Kelnar CJH. In: Endocrine disorders. Campbell AGM, McIntosh N, Kelnar CJH, eds. Forfar and Arneil's Textbook of Paediatrics. 4th Edn. Edinburgh: Churchill Livingstone, 1992:1111

15 Perheentupa J. In: The neurohypophysis and water regulation. Brook CGD, Perheentupa J, eds. Clinical Paediatric Endocrinology. 3rd Edn. Oxford: Blackwell Science, 1995:605.

16 Rennir JM. In: Fluid and eltrolyte balance. Roberton NRC, ed. Textbook of Neonatology. 2nd Edn. Edinburgh: Churchill Livingstone, 1992:239.

17 Baratz RA, Ingraham RC. Renal hemodynamics and antidiuretic hormone release associated with volume regulation. Am f Physiol 1960;198:565-70.

18 Tarak TK, Chaudhury RR. The mechanism of positive pressure respiration induced antidiuresis in the rat. Clin Sci 1965;28:407-13.

19 Baratz RA, Philbin DM, Patterson RW. Urinary output and plasma levels of antidiuretic hormone during intermittent positive-pressure breathing in the dog. Anesthesiology 1970;32:17-22.

20 Leslie GI, Phillips JB, Work J, Ram S, Cassady G. The effect of assisted ventilation on creatinine clearance and hormoin very low birth weight infants. Pediatr Res 1986;20:447-52.

21 Svenningsen NW, Andreasson B, Lindroth M. Diuresis and urine concentration during CPAP in newborn infants. Acta Paediatr Scand 1984;73:727-32.

22 Payen DM, Farge D, Beloucif S, Leviel F, De La Coussaye JE, Carli P, Wirquin V. No involvement of antidiuretic hormone in acute diuresis during PEEP ventilation in humans. Anesthesiology 1987;66:17-23.

23 Rees L, Forsling ML, Brook CGD. AVP concentrations in the neonatal period. Clin Endocrinol 1980;12:357-62.

24 McIntosh N, Smith A. Serial measurement of plasma AVP in newborn. Arch Dis Child 1985;60:1031-5.

25 Wiriyathian S, Rosenfeld CR, Arant BS, et al. Urinary arginine vasopressin: Pattern of excretion in the neonata period. Pediatr Res 1986;20:103-8.

26 Vanpee $M$, Herin P, Zetterstrom R, Aperia A. Postnatal development ofrenal function in very low birth-weight infants. Acta Paediatr Scand 1988;77:191-7. 